九州大学学術情報リポジトリ

Kyushu University Institutional Repository

\title{
Performance of Vegetative Growth and Artificial Fruit Body Formation of Hypsizygus marmoreus in Bang ladesh
}

Imtiaj, Ahmed

Department of Botany, University of Rajshahi

Sultana, Sharmin

Department of Botany, University of Rajshahi

Hossain, Jakir

Department of Botany, University of Rajshahi

Rahman, Syed Ajijur

Poverty Environment Network (PEN), Center for International Forestry Research (CIFIR)

他

https://doi.org/10.5109/1685879

出版情報：九州大学大学院農学研究院紀要. 61 (2)，pp. 257-262，2016-09-01. Faculty of Agriculture, Kyushu University

バージョン :

権利関係 : 


\title{
Performance of Vegetative Growth and Artificial Fruit Body Formation of Hypsizygus marmoreus in Bangladesh
}

\author{
Ahmed IMTIAJ ${ }^{1}$, Sharmin SULTANA ${ }^{1}$, Jakir HOSSAIN ${ }^{1}$, \\ Syed Ajijur RAHMAN² and Shoji OHGA* \\ Laboratory of Forest Resources management, Division of Forest Environment Sciences, \\ Department of Agro-Environment Sciences, Faculty of Agriculture, \\ Kyushu University, Sasaguri, Fukuoka 811-2415, Japan \\ (Received April 4, 2016 and accepted May 10, 2016)
}

\begin{abstract}
Hypsizygus marmoreus is an edible and medicinal mushroom belongs to Basidiomycetes. The optimal culture conditions for the vegetative growth of brown and white strains of $H$. marmoreus were investigated to obtain suitable farming condition. Temperature suitable and unsuitable for vegetative growth was obtained at 20 and $35^{\circ} \mathrm{C}$, respectively. The both strains of $H$. mermoreus love medium temperature and the mycelial growth was well developed at $20-25^{\circ} \mathrm{C}$. This mushroom prefer $\mathrm{pH}$ ranging $6-8$ for mycelial growth. The highest and lowest mycelial growth was found at $\mathrm{pH} 7$ and 5 of both strains, respectively. Among 5 different carbon sources, sucrose was the best, whereas, maltose and lactose were the worst. The most suitable nitrogen sources were $\mathrm{CaNO}_{3}$ (in brown strain $65.6 \mathrm{~mm}$ and in white strain $56.3 \mathrm{~mm}$ ) and the most unsuitable was $\mathrm{NH}_{4} \mathrm{H}_{2} \mathrm{PO}_{4}$ (in brown strain $44.02 \mathrm{~mm}$ and in white strain $40.2 \mathrm{~mm}$ ). Five different culture media were used to screen the optimal mycelial growth of H. marmoreus. PDA and YM (yeast-malt extract) were the most suitable and Czapek dox and Hennerberg were the most unfavorable for vegetative growth, whereas, glucose peptone was moderately suitable. The highest and lowest vegetative growth was observed in media prepared with mango (Mangifera indica) and koroi (Albizia procera) sawdust, respectively. However, for both strains, 3 weeks were required to complete mycelium running in mango sawdust, whereas, 4 weeks were spent to get $100 \%$ mycelium running in mahagoni (Swietenia mahagoni) and koroi sawdust. The premordia and fruiting bodies of $H$. marmoreus were formed in the mango sawdust medium sooner. The fruiting bodies of brown strain were formed earlier than white strain after occurrence of primordia. In case of limiting ventilation, the stem development was found to be good but no cap was seen to be formed. Ventilation influenced the growth and development of fruit body of $H$. marmoreus. Therefore, it could be said that physiochemical requirement for the vegetative growth is strictly considerable and results focused in this paper could be followed by farmers to scale up farming of $H$. marmoreus in Bangladesh.
\end{abstract}

Key words: Mushroom farming, Fruit body, Influencing factors, Substrates, Vegetative growth

\section{INTRODUCTION}

Hypsizygus marmoreus is one of the popular edible mushrooms cultivated world widely in autumn and winter with light brown or white umbrella- shaped small cap and known as shimeji or beech mushroom. This mushroom grows in a bunch and each cluster may include 15-50 individual plant showing attractive morphological approach. Shimeji should always be cooked since it is not a good mushroom to serve raw due to its somewhat bitter taste, but the bitterness disappears completely upon cooking. They are firm and crunchy in texture and they have a delicate mild, sweet flavor (Waites et al., 2001). $H$. marmoreus is also called Hypsizygus tessulatus belonging to Tricholomataceae, Agaricales, Hymenomycetidae, Basidiomycetes. Its taste is fresher than that of Pleurotus ostreatus, context is thicker than that of Pholiota nameko, character is more pliable than that of Lentinula edodes, and it even has unique fragrance of crab, so its mouth feel is good. Apart from its popular/exotic culinary status, $H$. marmoreus has exceptional medicinal

\footnotetext{
1 Department of Botany, University of Rajshahi, Rajshahi 6205, Bangladesh

2 Poverty Environment Network (PEN), Center for International Forestry Research (CIFIR), Jl Cifor, Situ Gede,Sindangbarang, Bogor Barat 16680, Indonesia

* Corresponding author (E-mail: ohga@forest.kyushu-u.ac.jp)
}

application including antitumour role. Matsuzawa (1998) reported that adding fruit bodies of beech mushroom to the diet of tumor-bearing mice resulted in a potent antitumor effect. Studies reported that $H$. marmoreus has an antioxidant effect (Matsuzawa et al., 1998) and an antiatherosclerotic effect that lowers total serum cholesterol (Mori et al., 2008). This mushroom contains complete set of 8 necessary amino acids and several kinds of polysaccharide. The extracts drawn by hot water or organic solvent from the fruit body has potential role to clears away the free radical of human body, which suggests that the mushroom has the effects of preventing and curing cancer, raising immunity, defending senescence and prolongs life. Moreover, polysaccharide, S-(1-3)D-glucan isolated from H. marmoreus, showed a very high antitumor activity (Akavia et al., 2009). Due to multipurpose uses; production and consumption is ever increasing of this medicinal mushrooms in the world. A lot of studies focused on its nutrient substances, physiological characters, and healthcare functions.

In general, it is recognized that growing mycelia in a defined medium is a rapid and alternative method to obtain fungal biomass for further use (Yang et al., 2009). Moreover, it is also well known that the mycelial cultivation of mushrooms is enhanced by different environmental and nutritional factors as well as propagation of mycelia is an earlier and essential step as spawning to culti- 
vate fruiting bodies of mushrooms. Comprehending this consequence, a proportional study has been conducted on the vegetative growth and artificial fruit body formation of $H$. marmoreus using different physiochemical factors to assess the optimal farming condition.

\section{MATERIALS AND METHODS}

\section{Mushroom sample}

The mycelial cultures of 2 strains (Brown-buna shimaji and White-bunapi shimaji) of $H$. marmoreus were collected from Kyushu University Mushroom Bank (KUMB), Japan and used in this experiment. To facilitate the study, strains of $H$. marmoreus were transferred to potato dextrose agar (PDA) plates and incubated at $23^{\circ} \mathrm{C}$ in the dark condition until they showed a full growth and then preserve at $8^{\circ} \mathrm{C}$ for further use. Unless otherwise stated, the tests were performed at least 3 times.

\section{Effects of temperature and $\mathrm{pH}$}

The experiment was conducted to screen the optimum temperature and $\mathrm{pH}$ for the mycelial growth of the mushroom. Five different temperatures (15, 20, 25, 30 and $35^{\circ} \mathrm{C}$ ) were used. A $5 \mathrm{~mm}$ diameter agar plug of an inoculum removed from 10 day old cultures grown on PDA and placed in the centre of each plate filled with $20 \mathrm{ml}$ of PDA. The medium was adjusted to $\mathrm{pH} 6$ and incubated for 10 days at $15,20,25,30$ and $35^{\circ} \mathrm{C}$ separately. Radial growth of mycelia on each Petri dish was measured at 3 directions and average value was calculated out of those 3 measurements. To calculate final mean value of mycelial growth of each strain, 3 replications were used. For pH effect, a $5 \mathrm{~mm}$ diameter agar plug of an inoculum was removed and placed similarly. The medium was adjusted to $\mathrm{pH}$ 5, 6, 7, 8 and 9 with the addition of $1 \mathrm{~N} \mathrm{NaOH}$ or $\mathrm{HCl}$, and incubated for 10 days at $23^{\circ} \mathrm{C}$. The measurement of mycelial growth was performed following same technique as optimum temperature tests.

\section{Effects of carbon and nitrogen sources}

To screen carbon and nitrogen sources favorable for the vegetative growth of selected mushroom strains, the tests were performed on potato agar (PA) medium following the modified technique used by Sung et al., 1993. Each of 5 carbon sources (fructose, glucose, lactose, maltose and sucrose) were supplemented at the concentration of $2 \mathrm{~g} / 100 \mathrm{ml}$ with PA medium separately. In case of each nitrogen source, $\mathrm{NH}_{4} \mathrm{H}_{2} \mathrm{PO}_{4}, \mathrm{CaNO}_{3}, \mathrm{KNO}_{3}, \mathrm{NaNO}_{3}$ and urea were supplemented separately at the concentration of $0.02 \mathrm{M}$ with $20 \mathrm{~g}$ of glucose to $100 \mathrm{ml}$ of PA medium. In both cases, the medium was adjusted to $\mathrm{pH} 6$ before autoclaving. To measure the colony diameter on the media, all plates were incubated for 10 days at $23^{\circ} \mathrm{C}$. Radial growth of mycelia was measured following same method which described earlier.

\section{Effects of culture media}

Five different culture media (Czapek dox, Hennerberg, Glucose peptone, PDA and YM) were pre- pared to investigate the mycelial growth of the strains. The media were adjusted to $\mathrm{pH} 6$ before autoclave. All culture media were inoculated with an inoculum similarly. After 10 days of incubation at $23^{\circ} \mathrm{C}$, measurement of mycelial growth was performed with same manner used before.

\section{Effect of sawdust and additives on mycelium run- ning}

To determine suitable additives for the mycelium running, sawdusts of Mangifera indica (mango), Albizia procera (koroi) and Swietenia mahagoni (mahagoni) were used with additives. The substrate was prepared supplimented (v/v) with $80 \%$ sawdust, $10 \%$ rice bran, $10 \%$ wheat bran and $1 \%$ calcium carbonate $\left(\mathrm{CaCO}_{3}\right)$ for mycelium running of $H$. marmoreus. After adding $60-70 \%$ water, round glass columns $(2 \mathrm{~cm} \times 22 \mathrm{~cm})$ were filled with individual sawdust mixture separately and autoclaved for 90 minutes at $121^{\circ} \mathrm{C}$. After $10-12$ hours cooling, all glass columns were inoculated with mother culture of $H$. marmoreus and incubated in a mycelium running room for 4 weeks at $23^{\circ} \mathrm{C}$. Thereafter, mycelial growth in glass columns was measured to screen out suitable substrate to propagate $H$. marmoreus and mycelial running rate (MRR) was noted.

\section{Conditions for primordial formation}

Similar method used for mycelium running was followed to testify the formation of premordia and fruiting body of $H$. marmoreus but polypropylene bottles $(12 \mathrm{~cm}$ $\times 30 \mathrm{~cm}$ ) were used in stead of glass columns. All bottles were inoculated with mother culture of $H$. marmoreus and incubated in a mycelium running room for 35 days at $23^{\circ} \mathrm{C}$. While substrates of all bottles were colonized with mycelia and turned into white color, excrete mycelial buff matter suggested its physiological maturation. Thereafter, bottles were opened and scratched mycelia from the neck and bottles were soaked with tap water for 3 hours and then incubate for $10-15$ days at $17^{\circ} \mathrm{C}$ under alternative 12 hours light (350 lux) and dark conditions with relative humidity of $95 \%$. After incubation, brown/white-milky colored primordia have been started to form on the top surface of the media.

\section{Effect of ventilation}

This experiemt was conducted in plastic boxes (18 inche $\times 15$ inche $\times 12$ inche) by filling the bottom of the boxes with tap water. Fourteen bottles of 35 days old spawn which were ready to form fruit body kept in the each plastic box. Then, three boxes were coverd with transference polyethylene and similar set of boxes maintained to cover and open at 6 hours interval. In both cases, incubation was maintained at $19^{\circ} \mathrm{C}$ for $10-15$ days. After incubation, the condition of cultures and fruit bodies in all boxes was obseved and recorded.

\section{RESULTS AND DISCUSSION}

\section{Effect of temperature}

The environmental requirements for the artificial veg- 
Table 1. Effect of temperature and $\mathrm{pH}$ on mycelial growth of $H$. marmoreus

\begin{tabular}{cccccc}
\hline \multirow{2}{*}{${ }^{\circ} \mathrm{C}$} & \multicolumn{2}{c}{ Mycelial growth $(\mathrm{mm})$} & \multicolumn{2}{c}{ Mycelial growth $(\mathrm{mm})$} & \multirow{2}{*}{$\mathrm{pH}$} \\
\cline { 2 - 4 } & Brown strain & White strain & White strain & Brown strain & \\
\hline \multirow{2}{*}{15} & 27.8 & 22.0 & 18.5 & 22.8 & 5 \\
20 & 75.6 & 71.8 & 26.2 & 32.8 & 6 \\
25 & 69.9 & 66.6 & 30.3 & 34.5 & 7 \\
30 & 38.1 & 35.9 & 29.4 & 35.4 & 8 \\
35 & 19.6 & 18.3 & 25.1 & 30.2 & 9 \\
\hline Mean & $\mathbf{4 6 . 2}$ & $\mathbf{4 2 . 9}$ & $\mathbf{2 5 . 9}$ & $\mathbf{3 1 . 1}$ & Mean \\
\hline
\end{tabular}

Mycelial growth was calculated $(\mathrm{n}=3)$ after 10 days of incubation and effect of $\mathrm{pH}$ on mycelial growth was recorded at $23^{\circ} \mathrm{C}$.

etative growth of 2 strains (brown and white) of $H$. marmoreus, an edible and delicious medicinal mushroom were studied. To screen the optimum temperature, 5 different temperatures $\left(15,20,25,30\right.$ and $\left.35^{\circ} \mathrm{C}\right)$ were studied (Table 1). The optimum temperature for the filamentous growth and density of studied mushroom was obtained at $20-25^{\circ} \mathrm{C}$. The lowest mycelial growth and density were recorded at $35^{\circ} \mathrm{C}$. The best mycelial growth of both white and brown strains of $H$. marmoreus was found at $20^{\circ} \mathrm{C}$. The both strains of $H$. marmoreus love medium-low temperature for adequate vegetative proliferation. Lee et al. (1999) and Shim et al. (2003) reported that the mycelial growth of Paecilomyces fumosoroseus had been expedited gradually in proportion to the rise of temperature and the most suitable was at $25^{\circ} \mathrm{C}$. Even though the mycelial growth of $P$. fumosoroseus was favorable at the range of $20-25^{\circ} \mathrm{C}$ and had been expedited in proportion to the rise of temperature, the mycelial growth appeared to be suppressed at the temperature higher than $30^{\circ} \mathrm{C}$. Shim et al. (2005) and Jo et al. (2006) stated that the favorable mycelial growth of Macrolepiota procera and Phellinus spp. was at $30^{\circ} \mathrm{C}$. Hur et al. (2008) observed the temperature effect on the mycelial growth of $P$. linteus and found that the temperature of $30^{\circ} \mathrm{C}$ was the best which does not comply with our result. Jayasinghe et al. (2008) studied the temperature effect on the mycelial growth of 8 strains belonging to Ganoderma lucidum and found suitable growth at $25^{\circ} \mathrm{C}$ with extension range of $20 \sim 30^{\circ} \mathrm{C}$. So, it could be said that the mushroom used in this experiment was different from the mushroom used by Shim et al., Jo et al. and Hur. Therefore, their results are not corresponded with that of our findings.

\section{Effect of pH}

Hydrogen ion concentration of the culture medium has a profound influence of overall metabolic activities of fungi. Highly acidic or alkalic media usually inhibit the growth of fungi and the minimum, optimum and maximum $\mathrm{pH}$ values as well as the $\mathrm{pH}$ range (5-9) for fungal mycelia was very considerable. Considering this, a research was conducted to screen out the suitable $\mathrm{pH}$ value for mycelial growth of $H$. marmoreus. This study found that the different strains may have an extensive
$\mathrm{pH}$ range for their spontaneous mycelial growth (Table 1). The highest mycelial growth of brown and white strains was found $35.4 \mathrm{~mm}$ and $30.3 \mathrm{~mm}$ at $\mathrm{pH} 7$ and 8 , respectively. For both strains, the lowest mycelial growth was found at $\mathrm{pH} 5$. It was found that $H$. marmoreus prefer alkalic to acidic condition of media. Shim et al. (2005) revealed that $\mathrm{pH} 7$ is the most suitable for the optimal growth of M. procera. Choi et al. (1999) and Chi et al. (1996) reported that mycelial growth of Phellinus japonica and $P$. linteus was optimal at $\mathrm{pH} 7$ and $6-7$, respectively. Shim et al. (2003) exposed that optimal pH was 8 for Paecilomyces sinclairii. Imtiaj et al. (2008a) observed the $\mathrm{pH}$ requirement for the vegetative growth of 10 strains of Schizophyllum commune and reported that $\mathrm{pH} 5$ was the best. After that decreased mycelial growth was found when $\mathrm{pH}$ value is gradually increased up to $\mathrm{pH}$ 9. This result suggested that mushrooms may have a broad $\mathrm{pH}$ range for their optimal mycelial growth in nature. The results of this study is completely similar to Shim et al. (2005), Shim et al. (2003), Choi et al. (1999) and Chi et al. (1996).

\section{Effect of carbon sources}

Carbon is the most required nutrient for mushroom. Carbon usually comes from organic compounds such as suger, organic acid, alcohols, starch, cellulose, hemi-celluloses and lignine. Five different carbon sources (glucose, fructose, lactose, maltose and sucrose) were used to find out the optimal farming condition and sucrose was the best carbon source for mycelial proliferation (Table 2). Fructose showed average mycelia growth of $H$. marmoreus. The lowest growth of vegetative development was obtained in maltose for both strains (brown strain $33.56 \mathrm{~mm}$ and white strain $28.90 \mathrm{~mm}$ ). This result is completely similar to Shim et al. (1997) but partially similar to Shim et al. (2005). Shim et al. (1997) reported that G. umbellata was favorable to maximum carbon sources except salicin, cellobiose and lactose. Shim et al. (2005) proved that sucrose, maltose, dextrin and mannose were effective where lactose was highly negative.

\section{Effect of nitrogen sources}

To find out the effects of nitrogen sources for mycelial growth, 5 nitrogen sources were used in this study. 
Table 2. Effect of carbon and nitrogen sources on mycelial growth of $H$. marmoreus

\begin{tabular}{|c|c|c|c|c|c|}
\hline \multirow{2}{*}{$\begin{array}{c}\text { Carbon } \\
\text { sources }\end{array}$} & \multicolumn{2}{|c|}{ Mycelial growth (mm) } & \multicolumn{2}{|c|}{ Mycelial growth (mm) } & \multirow{2}{*}{$\begin{array}{c}\text { Nitrogen } \\
\text { sources }\end{array}$} \\
\hline & Brown strain & White strain & White strain & Brown strain & \\
\hline Glucose & 37.60 & 32.09 & 48.30 & 50.90 & Urea \\
\hline Fructose & 39.60 & 32.20 & 56.30 & 65.60 & Calcium nitrate \\
\hline Lactose & 35.01 & 33.60 & 48.01 & 50.00 & Sodium nitrate \\
\hline Maltose & 33.56 & 28.90 & 50.30 & 55.05 & Potassium nitrate \\
\hline Sucrose & 40.70 & 36.06 & 40.20 & 44.02 & Amm. phosphate \\
\hline Mean & 37.29 & 32.57 & 48.622 & 53.114 & Mean \\
\hline
\end{tabular}

Mycelial growth was calculated $(n=3)$ after 10 days of incubation at $23^{\circ} \mathrm{C}$

Table 3. Effect of media on mycelial growth of $H$. marmoreus

\begin{tabular}{lcc}
\hline \multirow{2}{*}{ Media } & \multicolumn{2}{c}{ Mycelial growth (mm) } \\
\cline { 2 - 3 } & Brown strain & White strain \\
\hline Czapek dox (Cza) & 34.20 & 33.10 \\
Glucose peptone (GP) & 38.11 & 36.80 \\
Hennerberg (Hen) & 36.20 & 34.80 \\
Potato dextrose agar (PDA) & 53.50 & 50.30 \\
Yeast-malt extract (YM) & 43.90 & 41.30 \\
\hline Mean & $\mathbf{4 1 . 1 8}$ & $\mathbf{3 9 . 2 6}$ \\
\hline
\end{tabular}

Mycelial growth was calculated $(n=3)$ after 10 days of incubation at $23^{\circ} \mathrm{C}$.

The most suitable nitrogen sources were calcium nitrate (brown strain $65.6 \mathrm{~mm}$ and white strain $56.3 \mathrm{~mm}$ ), potassium nitrate (brown strain $55.05 \mathrm{~mm}$ and white strain $50.3 \mathrm{~mm}$ ) and average suitable was sodium nitrate (brown strain $50.00 \mathrm{~mm}$ and white strain $48.01 \mathrm{~mm}$ ) and Urea (brown strain $50.90 \mathrm{~mm}$ and white strain $48.3 \mathrm{~mm}$ ). The most unsuitable was ammonium phosphate (brown strain $44.02 \mathrm{~mm}$ and white strain $40.2 \mathrm{~mm}$ ). $\mathrm{CaNO}_{3}$, potassium nitrate showed moderately thin or thin mycelial density (Table 2). Most of the nitrogen sources showed compact mycelial density. Shim et al. (2005) clarified that glycine was the most favorable and histidine, arginine and ammonium oxalate were the most unfavorable for the mycelial growth of $M$. procera on the culture media. Lee et al., (2005) showed that soytone, malt extract, yeast extract and bacto-peptone were the most favorable but $\mathrm{NaNO}_{3}$ and urea were the most unfavorable for the mycelial growth of Ramaria botrytis.

\section{Screening of favorable culture media}

Five different culture media were used to screen the optimal vegetative growth of $H$. marmoreus. According to mycelial growth and density, PDA (brown strain 53.5 $\mathrm{mm}$ and white strain $50.3 \mathrm{~mm}$ ) and YM (brown strain $43.9 \mathrm{~mm}$ and white strain $41.3 \mathrm{~mm}$ ) were the most suitable. Glucose peptone (GP) was medium suitable (brown strain $38.11 \mathrm{~mm}$ and white strain $36.8 \mathrm{~mm}$ ). Czapek dox (brown strain $34.2 \mathrm{~mm}$ and white strain $33.1 \mathrm{~mm}$ ) and Hennerberg (brown strain $36.2 \mathrm{~mm}$ and white strain
$34.8 \mathrm{~mm}$ ) were the most unfavorable for vegetative growth of mushroom (Table 3). Besides of slow growth, mycelial density was also somewhat thin to thin on Czapek dox. This result is corresponded with that of Imtiaj et al. (2008b) where filamentous growth of Hericium erinaceus was the highest observed on PDA, YM, Hamada and GP media. Whereas, the lowest mycelial growth was counted on Czapek dox, Hoppkins, Lilly and Hennerberg. Shim et al. (2005) also reported similar mycelial growth of $P$. sinclairii and $P$. fumosoroseus found suitable on PDA, YM, Mushroom complete and Hamada.

\section{Effect of sawdusts on vegetative growth}

The experiment was conducted to study the effect of different sawdusts on the vegetative growth and yield of studied mushroom. The mycelial growth of $H$. marmoreus was observed for 4 weeks. The highest and lowest vegetative growth was observed in mango and koroi sawdust media, respectively. However, for both strains, 3 weeks were required to complete mycelium running in mango sawdust, whereas, 4 weeks were spent to get $100 \%$ mycelium running in mahagoni and koroi. The most slowest filamentous growth was recorded in koroi sawdust (Table 4).

The highest number of primordia per bottle filled with mango sawdust was counted 34 for brown and 28 for white strains. Whereas, the lowest number of primordia per bottle filled with koroi sawdust was noted 30 and 23 for brown and white strain, respectively. The sawdust of mahagoni showed moderate performance of premordia formation for both strains of the mushroom. The substrate of mango was promoted to produce fruiting bodies of 29 (brown) and 24 (white) strains. The highest biomass weight of brown ( $88 \mathrm{gm})$ and white $(73 \mathrm{gm})$ strain was obtained from mango sawdust and the lowest fresh weight of brown ( $80 \mathrm{gm})$ and white (61 gm) strain was recorded from koroi sawdust. The ongoing publicity of mushroom as a high source of protein with low cholesterol content which over ride meats and other fatty foods may soon get extra priority due to the use of sawdust as the best cheapest substrate for growing mushroom. It could be said that mango and mahagoni sawdusts are cellulose riched substrates suitable to grow $H$. mar- 
Table 4. Effect of carbon and nitrogen sources on mycelial growth of $H$. marmoreus

\begin{tabular}{|c|c|c|c|c|c|}
\hline \multirow{2}{*}{ Strain } & \multirow{2}{*}{ Substrate } & \multicolumn{4}{|c|}{ Mycelial growth (\%)/week } \\
\hline & & $1^{\text {st }}$ week & $2^{\text {nd }}$ week & $3^{\text {rd }}$ week & $4^{\text {th }}$ week \\
\hline \multirow{3}{*}{ Brown } & Mango (Mangifera indica) & 70.3 & 94.5 & 100 & \multirow{3}{*}{100} \\
\hline & Mahagoni (Swietenia mahagoni) & 35.2 & 67.5 & 97.0 & \\
\hline & Koroi (Albizia procera) & 34.0 & 53.3 & 76.3 & \\
\hline \multirow{3}{*}{ White } & Mango (Mangifera indica) & 65.4 & 90.4 & 100 & \multirow{3}{*}{100} \\
\hline & Mahagoni (Swietenia mahagoni) & 37.3 & 55.5 & 92.0 & \\
\hline & Koroi (Albizia procera) & 31.0 & 49.3 & 70.7 & \\
\hline
\end{tabular}

Incubation for mycelial growth was conducted $(n=3)$ at $23^{\circ} \mathrm{C}$

moreus, whereas, koroi sawdust is lignin abundant that is complex to degrade and unsuitable for studied mushroom. Shim et al. (2006b) found that fruiting bodies of Armillaria mellea were produced abundantly in the oak sawdust medium mixed with $10 \%$ rice bran but contamination rate seemed to be increased in proportion to the higher contents of rice bran. Semerdzieva et al. (1988) also reported that fruiting bodies of Oudemansiella radicata were formed very well in the oak sawdust medium mixed with $10 \%$ rice bran. Therefore, rice/wheat bran might contain some ingredients to facilitate the good mycelial growth of mushrooms and our result corrensponds with many evidences.

\section{Conditions for fruiting body formation}

After formation of the primordia, the bottles were transferred to cultivation room at $19^{\circ} \mathrm{C}$ under 12 hours of illumination (350 lux) and darkness with relative humidity of $95 \%$. The fruiting bodies of $H$. marmoreus were formed in the mango sawdust medium sooner. The fruiting bodies of brown strain were formed earlier than white strain after occurrence of primordia. In case of limiting ventilation, the stem development was found to be good but no cap was seen to be formed (Fig. 1). Imtiaj et al. (2008b) reported that $10 \%$ rice bran was better supplement with sawdust to produce fruiting bodies of Hericium erinaceus. Shim et al. (2006a) and Semerdzieva et al. (1988) also reported that fruiting bodies of $O$. radicata were formed very well in the oak sawdust medium mixed with $10 \%$ rice bran. Rew et al. (2004) showed that the mycelial growth of Phellinus baumii was best on oak sawdust mixed with $20 \%$ of rice bran (v/v). Shim et al. (2006a) reported that mycelial growth and density of $O$. radicata were also good on oak sawdust mixed with $10 \%$ rice bran that might contain some ingredients to facilitate the good mycelial growth of $O$. mucida and the other mushrooms.

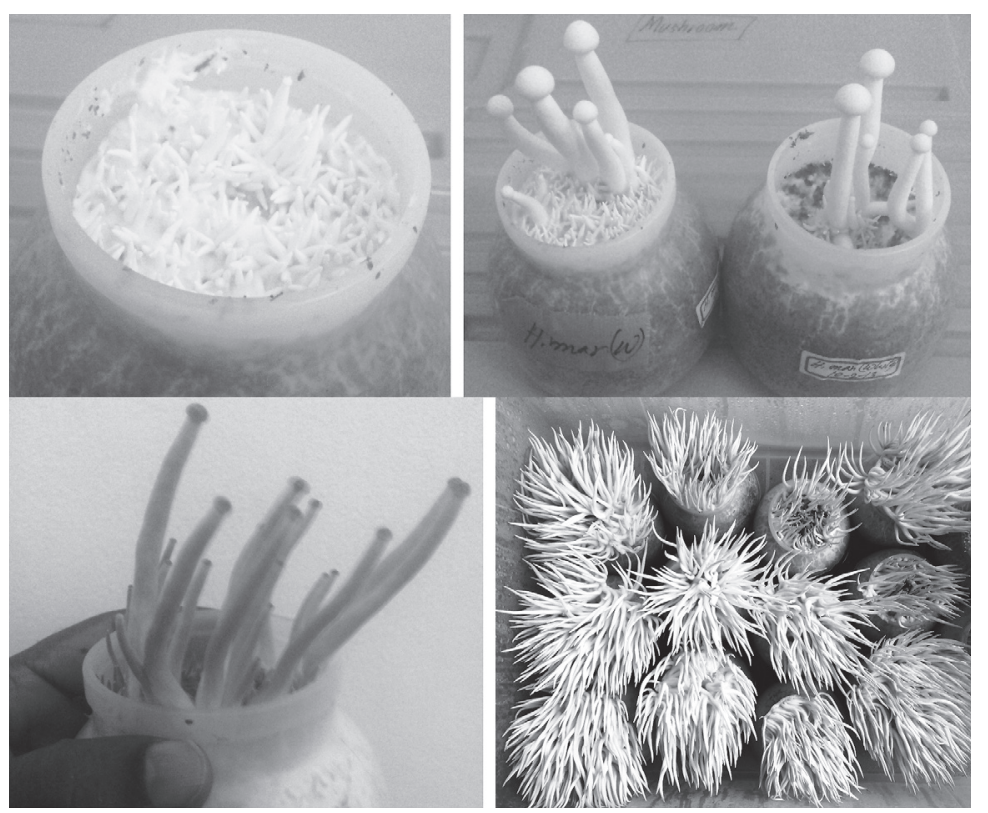

Fig. 1. Different stages of sporocarp of H. marmoreus. Premordia/pins formation of white strain (top-left), complete fruit body of white strain (topright), complete fruit body of brown strain (bottom-left), capless fruit body of brown strain (bottom-right). young fruit body (middle) and mature fruit body (right). 


\section{CONCLUSION}

This study was conducted for offering the best filamentous growth condition of brown and white strains of H. marmoreus. The requirement for the vegetative growth of 2 strains was slight different and vegetative growth of brown strain was faster than white strain in every case. Nowadays, we are devoted to improve the yield of biomass and quality of $H$. marmoreus through a new innovative experimental method by changing physicochemical factors, substrates and additives of the growing media. Ultimately, we might be able to produce commercially feasible basidiocarps of $H$. marmoreus using local agro-wastes and sawmill residues. After all, this is the first report associated with fruiting body production of H. marmoreus in Bangladesh.

\section{REFERENCES}

Akavia, E., A. Beharav, S. P. Wasser and E. Nevo 2009 Disposal of agro-industrial by-products by organic cultivation of the culinary and medicinal mushroom Hypsizygus marmoreus. Waste Manage, 29: 1622-1627

Chi, J. H., T. M. Ha, Y. H. Kim and Y. D. Rho 1996 Studies on the main factors affecting the mycelial growth of Phellinus linteus. Korean J. Mycol., 24: 214-222

Choi, Y. J., H. K. Hwang and W. H. Lee 1999 The production of artificial fruiting body of Paecilomyces japonica. Korean J. Mycol., 27: 87-93

Hur, H., A. Imtiaj, M. W. Lee and T. S. Lee 2008 Suitable conditions for mycelial growth of Phellinus spp. Mycobiology, 36: $152-156$

Imtiaj, A., C. Jayasinghe, G. W. Lee, H. Y. Kim, M. J. Shim, H. S. Rho, H. S. Lee, H. Hur, M. W. Lee, U. Y. Lee, and T. S. Lee 2008a Physicochemical requirement for the vegetative growth of Schizophyllum commune collected from different ecological origins. Mycobiology, 36: 34-39

Imtiaj, A., C. Jayasinghe, G. W. Lee, M. J. Shim, H. S. Rho, H. S. Lee, H. Hur, M. W. Lee, U. Y. Lee and T. S. Lee 2008b Vegetative growth of four strains of Hericium erinaceus collected from different habitats. Mycobiology, 36: 88-92

Jayasinghe, C., A. Imtiaj, H. Hur, G. W. Lee, T. S. Lee and U. Y. Lee 2008 Favorable culture conditions for mycelial growth of Korean wild strains in Ganoderma lucidum. Mycobiology, 36: $28-33$

Jo, W. S., Y. H. Rew, S. G. Choi, G. K. Seo, J. M. Sung and J. Y. Uhm 2006 The culture conditions for the mycelial growth of Phellinus spp. Mycobiology, 34: 200-205

Lee, I. K., H. J. Shim, S. D. Woo, Y. H. Je, Z. Yang and S. K. Kang 1999 Variation in growth and pathogenicity of Beauveria brassiana and Paecilomyces fumosoroseus pathogenic to the pine gall midge, Thecodiplosis japonensis. Korean J. Appl. Microb. Biotech., 27: 415-418

Lee, T. H. and H. H. Han 2005 Cultural characteristics for the enhanced mycelial growth of Ramaria botrytis. Mycobiology, 33: $12-14$

Matsuzawa T, H. Saitoh, M. Sano, I. Tomita, M. Ohkawa and T. Ikekawa 1998 Studies on antioxidant effects of Hypsizigus marmoreus, antioxidant activities of tumor-bearing mice. Yakugaku Zasshi, 118: 476-481

Mori K, C. Kobayashi, T. Tomita, S. Inatomi and M. Ikeda 2008 Antiatherosclerotic effect of the edible mushrooms Pleurotus eryngii (Eringi), Grifola frondosa (Maitake), and Hypsizygus marmoreus (Bunashimeji) in apolipoprotein E-deficient mice. Nutr. Res., 28: 335-342

Rew, Y. H., W. S. Cho, J. M. Lee and J. K. Kim 2004 Cultural characteristics of Phellinus baumii grown in bottle. Korean J. Mycol. 32: 101-104

Semerdzieva, M., A. S. Buchalo, P. Hobsch, O. A. Zakordonec, S. P. Wasser and V. Musilek 1988 Comparative study of cultures of four species of the genus Oudemansiella. Folia Microbiol., 33: 115-120

Shim, J. O., K. J. Chang, T. H. Kim, Y. S. Lee, U. Y. Lee, T. S. Lee and M. W. Lee 2006a The fruiting body formation of Oudemansiella radicata in the saw dust oak (Quercus variabilis) mixed with rice bran. Mycobiology, 34: 30-33

Shim, J. O., K. J. Chang, Y. S. Lee, C. H. Park, H. Y. Kim, U. Y. Lee, T. S. Lee and M. W. Lee $2006 \mathrm{~b}$ The fruiting body formation of Armillaria mellea on oak dust medium covered with raw carrots. Mycobiology, 34: 206-208

Shim, J. O., S. G. Son, Y. H. Kim, Y. S. Lee, J. Y. Lee, T. S. Lee, S. S Lee and M. W. Lee 1997 The culture conditions affecting the mycelial growth of Grifola umbellata. Korean J. Mycol., 25: 209-218

Shim, S. M., K. R. Lee, S. H. Kim, K. H. Im, J. W. Kim, U. Y. Lee, J. O. Shim, M. W. Lee and T. S. Lee 2003 The optimal culture conditions affecting the mycelial growth and fruiting body formation of Paecilomyces fumosoroseus. Mycobiology, $\mathbf{3 1}$ $214-220$

Shim, S. M., Y. H. Oh, K. R. Lee, S. H. Kim, K. H. Im, J. W. Kim, U. Y Lee, J. O. Shim, M. J. Shim, M. W. Lee, H. S. Ro, H. S. Lee, and T. S. Lee 2005 The characteristics of culture conditions for the mycelial growth of Macrolepiota procera. Mycobiology, 33: $15-18$

Sung, J. M., C. H. Kim, K. J. Yang, H. K. Lee and Y. S. Kim 1993 Studies on distribution and utilization of Cordyceps militaris and C. nutans. Korean J. Mycol., 21: 94-105

Waites, M. J., N. L. Morgan, J. S. Rockey and G. Higton 2001 Industrial Microbiology: An Introduction. John Wiley and Sons, Oxford, ISBN: 9780632053070, pp: 169-170

Yang, F. C., M. J. Yang and S. H. Cheng 2009 A novel method to enhance the mycelia production of Ganoderma lucidum in submerged cultures by polymer additives and agitation strategies. J. Taiwan Institute of Chem. Eng., 40: 148-154 